\title{
An Integrative Approach to Understand the Climatic-Hydrological Process: A Case Study of Yarkand River, Northwest China
}

\author{
Jianhua Xu, Yiwen Xu, and Chunan Song \\ The Research Center for East-West Cooperation in China, The Key Lab of GIScience of the Education Ministry PRC, \\ East China Normal University, 500 Dongchuan Road, Minhang, Shanghai 200241, China
}

Correspondence should be addressed to Jianhua Xu; jhxu@geo.ecnu.edu.cn

Received 5 February 2013; Accepted 8 April 2013

Academic Editor: Luis Gimeno

Copyright (C) 2013 Jianhua Xu et al. This is an open access article distributed under the Creative Commons Attribution License, which permits unrestricted use, distribution, and reproduction in any medium, provided the original work is properly cited.

Taking the Yarkand River as an example, this paper conducted an integrative approach combining the Durbin-Watson statistic test (DWST), multiple linear regression (MLR), wavelet analysis (WA), coefficient of determination (CD), and Akaike information criterion (AIC) to analyze the climatic-hydrological process of inland river, Northwest China from a multitime scale perspective. The main findings are as follows. (1) The hydrologic and climatic variables, that is, annual runoff (AR), annual average temperature, (AAT) and annual precipitation (AP), are stochastic and, no significant autocorrelation. (2) The variation patterns of runoff, temperature, and precipitation were scale dependent in time. AR, AAT, and AP basically present linear trends at 16-year and 32-year scales, but they show nonlinear fluctuations at 2-year and 4-year scales. (3) The relationship between AR with AAT and AP was simulated by the multiple linear regression equation (MLRE) based on wavelet analysis at each time scale. But the simulated effect at a larger time scale is better than that at a smaller time scale.

\section{Introduction}

The hydrological response to climate change is an important science issue. To well understand this issue, the coupled system of climatic-hydrological process should be thoroughly studied at different spatial and temporal scales.

Theoretically, a process can be evaluated to determine if they comprise an ordered, deterministic system, an unordered, random system, or a chaotic, dynamic system, and whether change patterns of periodicity or quasi-periodicity exist. However, it is difficult to achieve a thorough understanding of the mechanism of climatic-hydrological processes [1]. To date, these questions have not received satisfactory answers [2].

Case studies in different countries and regions have suggested that the climatic-hydrological process is a complex system [3-6]. Therefore, more studies are required to explore the mechanism of climatic-hydrological process from different perspectives and using different methods. As a result, the climatic-hydrological process has been explored using various analytical methods, including the fractal theory [79], self-organized criticality [10], wavelets analysis [11-13], and artificial neural networks $[14,15]$. Although there were several effective methods available to reveal the variations in climatic-hydrological process [16-19], it has proven difficult to achieve a thorough understanding of the mechanism of climatic-hydrological process in inland river [2].

In the last 20 years, studies have been conducted to evaluate climate change and hydrological and ecological processes in the arid and semiarid regions in northwestern China [18-25]. Some studies have indicated that there was a visible transition in the hydroclimatic processes in the past half-century [24, 26-28]. This transition was characterized by a continual increase in temperature and precipitation, added river runoff volumes, increased lake water surface elevation and area, and elevated groundwater level. This transition may present a series of questions if these changes represent a localized transition to a warm and wet climate type in response to global warming, or merely reflect a centennial periodicity in hydrological dynamics. To date, these questions 
have not received satisfactory answers; therefore, more studies are required to explore the nonlinear characteristics of hydroclimatic process from different perspectives and using different methods $[2,15,29]$.

Though some studies have shown that the inland river in northwest China (NW China), such as the Yarkand River, is mainly recharged by snowmelt, the main climatic factors affecting the streamflow are temperature and precipitation $[20,30,31]$. But due to the complexity of hydroclimatic system, it is difficult to understand the mechanism of climatichydrological process thoroughly [2]. For the above reasons, this paper did not involve the complex physical mechanisms but conducted an integrative approach combining statistics and wavelet analysis to understand the variation of annual runoff and its response to climatic factors at different time scales.

\section{Materials and Methods}

2.1. Study Area and Data. The Yarkand River is a typical representative of inland rivers, which is located in the Tarim River Basin of Xinjiang Uygur Autonomous Region, northwestern China (Figure 1), with a length of $1097 \mathrm{~km}$. The Yarkand River $\left(35^{\circ} 40^{\prime} \sim 40^{\circ} 31^{\prime} \mathrm{N}, 74^{\circ} 28^{\prime} \sim 80^{\circ} 54^{\prime} \mathrm{E}\right)$ has a total basin area of $9.89 \times 10^{4} \mathrm{~km}^{2}$, including $6.08 \times 10^{4} \mathrm{~km}^{2}$ as the mountain area, which accounts for $61.5 \%$, and $3.81 \times$ $10^{4} \mathrm{~km}^{2}$ as the plain area, which takes up $38.5 \%$ [31]. The main stream of Yarkand River originates from Karakoram Pass in the north slope of Karakoram Mountain, which is full of towering peaks and glaciers, as well as the extremely rare precipitation in plain. Due to the special geographical conditions, the accumulation of ice and snow in high mountain is the only supply source for runoff. Therefore, the Yarkand River is a typical ice-snow supply river, in which the multiyear average runoff in Kaqun hydrometric station consists of $64.0 \%$ from mean volume of glacial ablation, $13.4 \%$ from rain and snow supply, and $22.6 \%$ from groundwater supply, respectively $[32,33]$.

For the Yarkand River is an inland river, no water recharges in the plain area, and its stream flow mainly comes from mountainous area, that is, the Pamir Mountains. In other words, the streamflow of the Yarkand River is mainly fed by glacier and snowmelt in the Pamir Mountains. Therefore, the climatic factors, especially temperature and precipitation, directly affect the annual changes in the runoff. So we use the runoff as well as temperature and precipitation data to analyze the climatic-hydrological process in Yarkand River. The runoff data were from the Kaqun hydrologic station, and temperature and precipitation data were from Tash Kurghan meteorological station. The two stations are located in the source areas of the river; the amount of water used by humans is minimal compared to the total discharge. Therefore, the observed hydrological and meteorological records reflect the natural conditions.

Long-term climate changes can alter the runoff production pattern, the timing of hydrological events, and the frequency and severity of floods, particularly in arid or semiarid regions. Therefore, a small change in precipitation and temperature may result in marked changes in runoff. To investigate the runoff and its related climatic effect, this study used the time series data of annual runoff (AR), annual average temperature (AAT), and annual precipitation (AP) from 1957 to 2008 .

2.2. Methods. In order to study the variations of streamflow with regional climate change at different time scales, this paper conducted a comprehensive method including the Durbin-Watson statistic test (DWST), multiple linear regression (MLR), wavelet analysis (WA), coefficient of determination (CD), and Akaike information criterion (AIC). Firstly, the DWST was used to explore the stochastic characteristic of hydrologic and climatic variables. Secondly, the WA was used to reveal the variation patterns of annual runoff (AR) and its related climatic factors at different time scales. Thirdly, the relationship between AR with AAT and AP was simulated by MLR based on WA at different time scales. Finally, the estimated effect of multiple linear regression equation (MLRE) at each time scale was tested by CD and AIC.

2.2.1. Durbin-Watson Statistic Test. The Durbin-Watson statistic is a test statistic used to detect the presence of autocorrelation (a relationship between values separated from each other by a given time lag) in the residuals (prediction errors) from a regression analysis [34, 35].

For a variable $y$, the Durbin-Watson statistic is

$$
\mathrm{DW}=\frac{\sum_{i=2}^{n}\left(e_{i}-e_{i-1}\right)^{2}}{\sum_{i=1}^{n} e_{i}^{2}},
$$

where $e_{i}=y_{i}-\widehat{y}_{i}$, and $y_{i}$ and $\widehat{y}_{i}$ are, respectively, the observed and predicted values of the response variable for individual $i$; $n$ is the number of observations.

To test for positive autocorrelation at significance $\alpha$, the test statistic DW is compared to lower and upper critical values $\left(d_{L}\right.$ and $\left.d_{U}\right)$ : if DW $<d_{L}$, there is statistical evidence that the error terms are positively autocorrelated; if DW > $d_{U}$, there is no statistical evidence that the error terms are positively autocorrelated; if $d_{L}<\mathrm{DW}<d_{U}$, the test is inconclusive.

To test for negative autocorrelation at significance $\alpha$, the test statistic $4-\mathrm{DW}$ is compared to lower and upper critical values $\left(d_{L}\right.$ and $\left.d_{U}\right)$ : if $(4-\mathrm{DW})<d_{L}$, there is statistical evidence that the error terms are negatively autocorrelated; if $(4-\mathrm{DW})>d_{U}$, there is no statistical evidence that the error terms are negatively autocorrelated; if $d_{L}<(4-\mathrm{DW})<d_{U}$, the test is inconclusive.

Using the Durbin-Watson statistic, we checked the autocorrelation of hydrological and climatic variables, such as temperature, precipitation, and runoff.

2.2.2. Wavelet Analysis. Wavelet transformation has been shown to be a powerful technique for characterization of the frequency, intensity, time position, and duration of variations in climate and hydrological time series $[11,12,16$, 36]. Wavelet analysis can also reveal the localized time and frequency information without requiring the time series to 


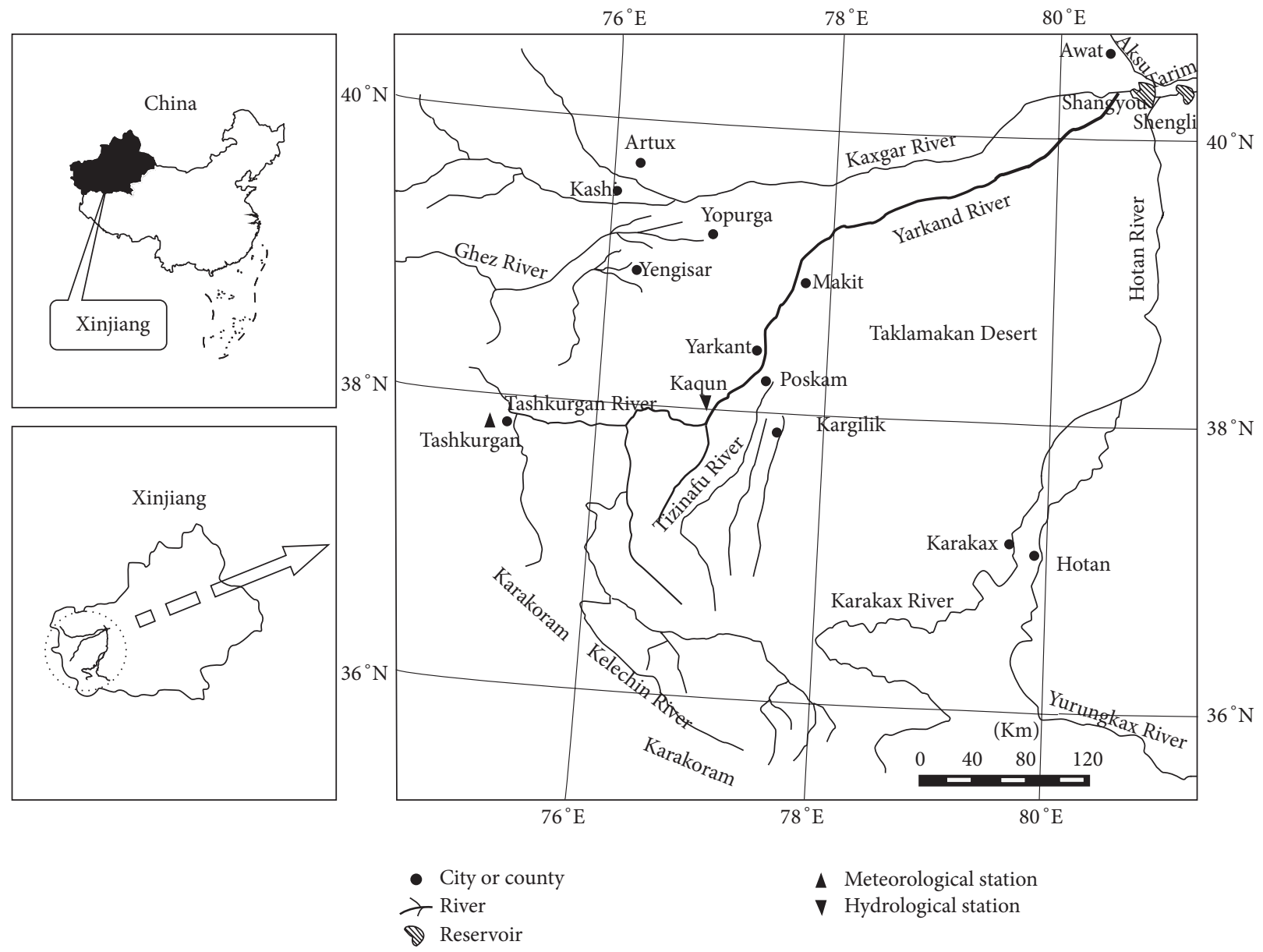

Figure 1: Location of the Yarkand River.

be stationary, as required by the Fourier transform and other spectral methods [37].

A continuous wavelet function $\Psi(\eta)$ that depends on a nondimensional time parameter $\eta$ can be written as [36]

$$
\Psi(\eta)=\Psi(a, b)=|a|^{-1 / 2} \Psi\left(\frac{t-b}{a}\right),
$$

where $t$ denotes time, $a$ is the scale parameter, and $b$ is the translation parameter. $\Psi(\eta)$ must have a zero mean and be localized in both time and Fourier space [38]. The continuous wavelet transform (CWT) of a discrete signal, $x(t)$, such as the time series of runoff, temperature, or precipitation, is expressed by the convolution of $x(t)$ with a scaled and translated $\Psi(\eta)$,

$$
W_{x}(a, b)=|a|^{-1 / 2} \int_{-\infty}^{+\infty} x(t) \Psi^{*}\left(\frac{t-b}{a}\right) d t,
$$

where * indicates the complex conjugate, and $W_{x}(a, b)$ denotes the wavelet coefficient. Thus, the concept of frequency is replaced by that of scale, which can characterize the variation in the signal, $x(t)$, at a given time scale.

Selecting a proper wavelet function is a prerequisite for time series analysis $[39,40]$. The actual criteria for wavelet selection include self-similarity, compactness, and smoothness [41]. Because the symlets are nearly symmetrical, orthogonal, and biorthogonal wavelets proposed by Daubechies as modifications to the db family [41], this study chose the symlets 8 to analyze the variation patterns of runoff and its related climatic factors in the computing environment of MATLAB.

For a time series, $x(t)$, it can be analyzed at multiple scales through wavelet decomposition on the basis of the discrete wavelet transform (DWT). The DWT is defined taking discrete values of $a$ and $b$. The full DWT for signal, $x(t)$, can be represented as [42]

$$
x(t)=\sum_{k} \mu_{j_{0}, k} \phi_{j_{0}, k}(t)+\sum_{j=1}^{j_{0}} \sum_{k} \omega_{j, k} \psi_{j, k}(t),
$$

where $\phi_{j_{0}, k}(t)$ and $\psi_{j, k}(t)$ are the flexing and parallel shift of the basic scaling function, $\phi(t)$, and the mother wavelet function, $\psi(t)$, and $\mu_{j_{0}, k}\left(j<j_{0}\right)$ and $\omega_{j, k}$ are the scaling coefficients and the wavelet coefficients, respectively. Generally, scales and positions are based on powers of 2 , which is the dyadic DWT. 
Once a mother wavelet is selected, the wavelet transform can be used to decompose a signal according to scale, allowing separation of the fine-scale behavior (detail) from the large-scale behavior (approximation) of the signal [43]. The relationship between scale and signal behavior is designated as follows: low scale corresponds to compressed wavelet as well as rapidly changing details, namely, high frequency; whereas high scale corresponds to stretched wavelet and slowly changing coarse features, namely, low frequency. Signal decomposition is typically conducted in an iterative fashion using a series of scales such as $a=2,4,8, \ldots, 2^{L}$, with successive approximations being split in turn so that one signal is broken down into many lower resolution components.

The wavelet decomposition and reconstruction were used to approximate the variation patterns of $\mathrm{AR}$ and its related factors over the entire study period at the selected different time scales.

2.2.3. Multiple Linear Regression. For understanding the relationship between annual runoff with its related climatic factors at different time scales, we employed multiple linear regression (MLR) based on wavelet analysis. This method fits multiple linear regression equation (MLRE) between AR with AAT and AP by using multiple linear regression (MLR) based on the results of wavelet approximation [44].

The multiple linear regression model is

$$
y=a_{0}+a_{1} x_{1}+a_{2} x_{2}+\cdots+a_{k} x_{k}
$$

where $y$ is dependent variable, $x_{i}$ is the independent variables; $a_{i}$ is the regression coefficient, which is generally calculated by method of least squares [45]. In this study, the dependent variable is the annual runoff (AR) and the independent variables are related climatic factors, such as the annual average temperature (AAT) and annual precipitation (AP).

2.2.4. Coefficient of Determination and Akaike Information Criterion. In order to identify the uncertainty of the estimated model for a given time scale, the coefficient of determination, also known as the goodness of fit, was calculated as follows:

$$
R^{2}=1-\frac{\mathrm{RSS}}{\mathrm{TSS}}=1-\frac{\sum_{i=1}^{n}\left(y_{i}-\hat{y}_{i}\right)^{2}}{\sum_{i=1}^{n}\left(y_{i}-\bar{y}\right)^{2}},
$$

where $R^{2}$ is the coefficient of determination; $\widehat{y}_{i}$ and $y_{i}$ are the simulated value and actual data of runoff, respectively; $\bar{y}$ is the mean of $y_{i}(i=1,2, \ldots, n)$; RSS $=\sum_{i=1}^{n}\left(y_{i}-\widehat{y}_{i}\right)^{2}$ is the residual sum of squares; TSS $=\sum_{i=1}^{n}\left(y_{i}-\bar{y}\right)^{2}$ is the total sum of squares.

The coefficient of determination is a measure of how well the simulated results represent the actual data. A bigger $R^{2}$ indicates a higher certainty and lower uncertainty of the estimates [45].

To compare the relative goodness between the ANN and multiple linear regression (MLR) fit for a given timescale, we also used the measure of Akaike information criterion (AIC) [46]. The formula of AIC is as follows:

$$
\mathrm{AIC}=2 k+n \ln \left(\frac{\mathrm{RSS}}{n}\right)
$$

where $k$ is the number of parameters estimated in the model; $n$ is the number of samples; RSS is the same as in formula (6). A smaller AIC indicates a better model.

For small sample sizes (i.e., $n / K \leq 40$ ), the second-order Akaike information criterion $\left(\mathrm{AIC}_{c}\right)$ should be used instead:

$$
\mathrm{AIC}_{c}=\mathrm{AIC}+\frac{2 k(k+1)}{n-k-1},
$$

where $n$ is the sample size. As the sample size increases, the last term of the $\mathrm{AIC}_{c}$ approaches zero, and the $\mathrm{AIC}_{c}$ tends to yield the same conclusions as the AIC [47].

\section{Results}

3.1. Check for Variable's Autocorrelation. The premise of statistics indicates that models imply an assumption; that is, variables are stochastic and no significant autocorrelation is present. Is it really? This can be demonstrated by statistical check for variable's autocorrelation (Table 1$)$.

For $\left(1^{*}\right),\left(2^{*}\right)$, and $\left(3^{*}\right)$ in Table 1 , their degree of freedom is, respectively, $k$ equals 2 and $N$ (i.e., $n-k-1$ ) equals 51. Upper and lower critical values of the Durbin-Watson Statistic (DW) are $d_{L}$ equals 1.509 and $d_{U}$ equals 1.58 when significance level $(\alpha)$ equals 0.01 . Because the values of DW are between $d_{U}$ and $4-d_{U}$, it is obvious that annual runoff (AR), annual average temperature (ATT), and annual precipitation (AP) indicate no autocorrelation.

For $\left(4^{*}\right)$ in Table 1, its degree of freedom is, respectively, $k$ equals 4 and $N$ equals 51 . Upper and lower critical values of DW are $d_{L}$ equals 1.25350 and $d_{U}$ equals 1.49384 when significance level $(\alpha)$ equals 0.01 . For $\left(5^{*}\right)$, its degree of freedom is, respectively, $k$ equals 6 and $N$ equals 51. Upper and lower critical values of DW are $d_{L}$ equals 1.17372 and $d_{U}$ equals 1.58811 when significance level $(\alpha)$ equals 0.01 . Thereby they indicate no autocorrelation either.

In fact, it can be determined that variables and model reveal non-autocorrelation because the value of DW is close to 2 for each regression equation shown in Table 1 . Therefore, the assumption of our model is logical.

3.2. Variation Patterns of Climatic-Hydrological Process at Different Time Scales. Our previous study indicated that [44] the annual average temperature and annual precipitation are the most important factors that related with the annual runoff. The result was also supported by the other studies for the headwaters of the Tarim River Basin [20, 30-33].

The raw data of AR, AAT, and AP showed fluctuation. It is difficult to identify any patterns simply based on the raw data. In order to show the scale-dependent with time for the climatic-hydrological process of the Yarkand River, the wavelet analysis was used. The nonlinear variation for the annual runoff process and the related climate factors were 
TABLE 1: Statistical check for variable's autocorrelation.

\begin{tabular}{|c|c|c|c|c|c|c|}
\hline $\begin{array}{l}\text { Dependent } \\
\text { variable }\end{array}$ & $\begin{array}{c}\text { Independent } \\
\text { variable }\end{array}$ & Function & & $R^{2}$ & $F$ & DW \\
\hline $\mathrm{AR}_{t}$ & $\mathrm{AR}_{t-1}$ & $\mathrm{AR}_{t}=76.852-0.156 \mathrm{AR}_{t-1}$ & $\left(1^{*}\right)$ & 0.024 & 1.125 & 1.981 \\
\hline $\mathrm{AAT}_{t}$ & $\mathrm{AAT}_{t-1}$ & $\mathrm{AAT}_{t}=2.526-0.290 \mathrm{AAT}_{t-1}$ & $\left(2^{*}\right)$ & 0.093 & 5.014 & 1.835 \\
\hline $\mathrm{AP}_{t}$ & $\mathrm{AP}_{t-1}$ & $\mathrm{AP}_{t}=81.338-0.118 \mathrm{AP}_{t-1}$ & $\left(3^{*}\right)$ & 0.013 & 0.659 & 1.851 \\
\hline $\mathrm{AR}_{t}$ & $\mathrm{AAT}_{t}, \mathrm{AP}_{t}, \mathrm{AR}_{t-1}$ & $\mathrm{AR}_{t}=66.677+3.191 \mathrm{AAT}_{t}-0.025 \mathrm{AP}_{t}-0.145 \mathrm{AR}_{t-1}$ & $\left(4^{*}\right)$ & 0.091 & 1.572 & 2.023 \\
\hline $\mathrm{AR}_{t}$ & $\begin{array}{c}\mathrm{AAT}_{t}, \mathrm{AP}_{t}, \mathrm{AR}_{t-1} \\
\mathrm{AAT}_{t-1}, \mathrm{AP}_{t-1}\end{array}$ & $\mathrm{AR}_{t}=62.516+2.051 \mathrm{AAT}_{t}-0.048 \mathrm{AP}_{t}-0.186 \mathrm{AR}_{t-1}+2.702 \mathrm{AAT}_{t-1}+0.042 \mathrm{AP}_{t-1}$ & $\left(5^{*}\right)$ & 0.123 & 1.266 & 1.931 \\
\hline
\end{tabular}

Notes. AR: annual runoff, AAT: annual average temperature, and AP: annual precipitation; the subscripts, $t$ and $t-1$, represent time.

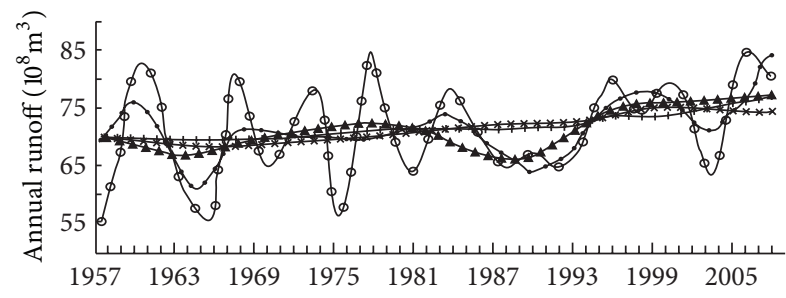

(a)

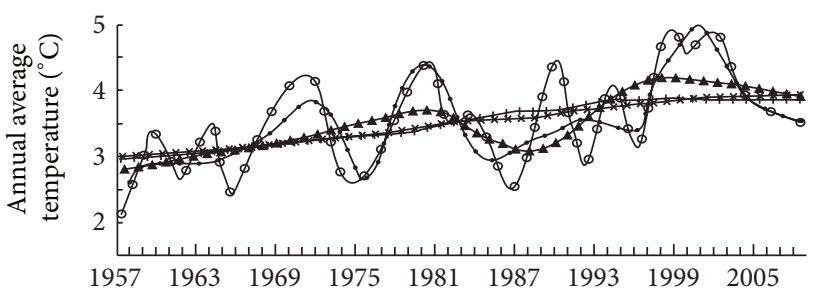

(b)

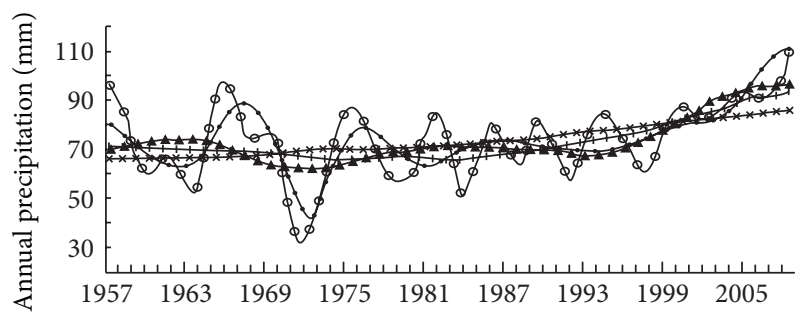

$\multimap$ S1 (the time scale of 2 years) $\longrightarrow$ S4 (the time scale of 16 years)
$\longrightarrow$ S2 (the time scale of 4 years) $\rightarrow$ S5 (the time scale of 32 years)
$\simeq$ S3 (the time scale of 8 years)

(c)

FIgURE 2: Variation patterns at different time scales of (a) annual runoff, (b) annual average temperature, and (c) annual precipitation.

analyzed at multiple-year scales through wavelet decomposition on the basis of the discrete wavelet transform (DWT).

The wavelet decomposition for the time series of annual runoff at five time scales resulted in five variation patterns (Figure 2(a)). The S1 curve retains a large amount of residual from the raw data, and drastic fluctuations exist in the period from 1957 to 2008 . These characteristics indicate that although the runoff varied greatly throughout the study period, there was a hidden increasing trend. The S2 curve still retains a considerable amount of residual, as indicated by the presence of 4 peaks and 4 valleys. However, the S2 curve is much smoother than the S1 curve, which allows the hidden increasing trend to be more apparent. The S3 curve retains much less residual, as indicated by the presence of 2 peaks and 2 valleys. Compared to S2, the increase in runoff over time is more apparent in S3. Finally, the S5 curve presents an ascending tendency, whereas the increasing trend is obvious in the $\mathrm{S} 4$ curve.

Accordingly, Figures 2(b) and 2(c) provide us with a method for comparing the variation patterns of annual average temperature and annual precipitation at different time scales. The wavelet decomposition for the time series at five time scales resulted in five variation patterns, respectively. These five time scales are also designated as S1 to S5. The curves present an ascending tendency despite drastic fluctuations in S1 and S2. Then, the curves are getting much smoother and the increasing trend becomes even more obvious as the scale level increases.

The upper analysis showed that the nonlinear variations of runoff, temperature, and precipitation of the Yarkand River basin were dependent on time scales. The annual runoff, annual average temperature and annual precipitation at five time scales resulted in five patterns of nonlinear variations, respectively.

3.3. Relationship between Streamflow and Climate Factors. Based on the raw data of AAT, AP, and AR, multiple linear regression equation (MLRE) was developed as follows:

$$
\begin{gathered}
\mathrm{AR}=3.5 \mathrm{AAT}-0.037 \mathrm{AP}+56.75, \\
R^{2}=0.1983, \quad F=2.517, \quad \alpha=0.1 .
\end{gathered}
$$

Equation (9) reveals a positive correlation between the annual runoff and the annual average temperature. These results are readily supported by the fact that the majority of streamflow comes from glacial melt and snowmelt, which have been occurring at increased rates as the temperature increases. These results have been confirmed by other studies [48]. However, (9) also indicates the existence of a weak, negative correlation between the annual runoff and the annual precipitation, which does not seem reasonable. Indeed, this finding conflicts with the results of other studies, which have suggested that both the temperature and precipitation series in the Tarim Basin have been increasing in a pattern similar to that of annual runoff over the past 50 years $[20,30]$. 
Additionally, the coefficient of determination of (9) is as low as 0.093 . Furthermore, the average absolute error and average relative error for predicted results is as high as $9.014 \times 10^{8} \mathrm{~m}^{3}$ and $14.11 \%$, respectively. All this means that the regression (9) is not authentic. What is the reason for this? It is possible that this inconsistency is caused by randomicity in the raw time-series data, which should be filtered out via wavelet decomposition based on the discrete wavelet transform $[17,18]$.

To understand the response of the runoff to regional climatic change at different time scales, based on the results of wavelet decomposition (Figure 2), multiple linear regression equation (MLRE) at each time scale was fitted for describing the relationship among annual runoff, annual average temperature, and annual precipitation (Table 2).

3.4. Comparison of the Estimated Results at Different Time Scales. Though all MLREs at each time scale in Table 2 got across the statistical test at the significant level of 0.01 or 0.001 , the predicted error of MLRE at the chosen time scales is different. Figure 3 shows the comparison for the simulated value by MLREs and original data of AR at different time scales. The predicted error of MLRE at the time scale of S1 and S2 (i.e., 2-year and 4-year scales) is large, that at the time scale of S3 (i.e., 8-year scale) is also fairish, and wee predicted error of MLRE at the time scale of S4 and S5 (i.e., 4-year and 5 -year scales) appears. These results show that MLRE only can well fit the relationship between runoff and climate factors at large time scale such as at 16-year and 32-year scales.

By comparing the $R^{2}$ and AIC value in Table 3 , we can know the estimated effect (good or bad) of models at different time scales.

Table 3 tells us that the $R^{2}$ for MLRE at the time scale of S1 and S2 (i.e., 2-year and 4-year scales) is lower (only 0.361 and 0.416 , resp.) and that at the time scale of S3 (i.e., 8-year scales) is higher, reaching 0.894 . Only the MLRE at the time scale of S4 and S5 (i.e., 16-year and 32-year scales) has the high coefficient of determination, which is as high as 0.975 and 0.996 , respectively.

The lower AIC value indicates better model, which tells us that the MLRE at time scale of S5 is the best, that at time scale of S4 is better, that at time scale of S3 is moderate, that at time scale of $\mathrm{S} 2$ is the penult, and that at time scale of $\mathrm{S} 1$ is the worst.

Overall, the relationship between AR with AAT and AP was simulated by the multiple linear regression (MLR) based on wavelet analysis at different time scales, but the simulated effect at a larger time scale is better than that at a smaller time scale.

\section{Discussion and Conclusions}

Many studies indicated that the climatic-hydrological process is a complex system with nonlinearity, but it is difficult to understand the mechanism of climatic-hydrological process thoroughly [2]. Our results showed the following fact: the simulated effect at large time scale is better than that at small time scale, and the estimated precision at large time scale is

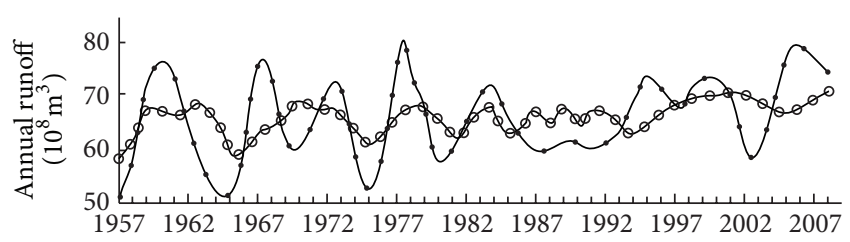

(a) S1 (the time scale of 2-year)

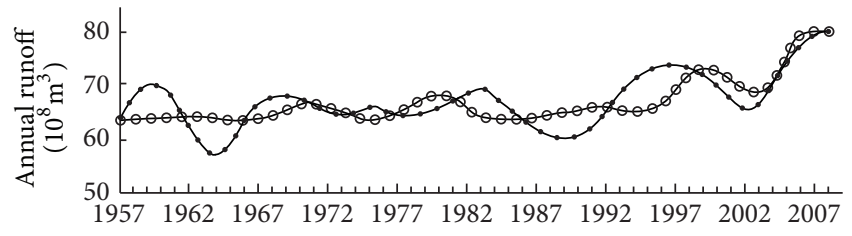

(b) S2 (the time scale of 4-year)

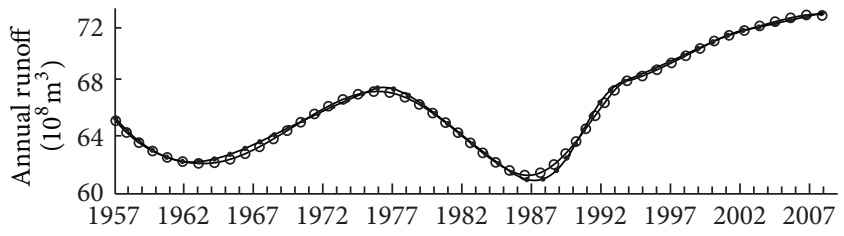

(c) S3 (the time scale of 8-year)

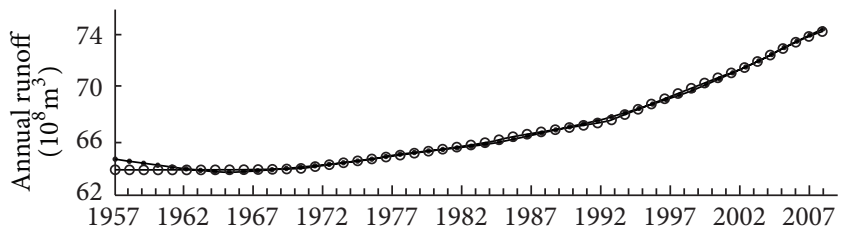

(d) S4 (the time scale of 16-year)

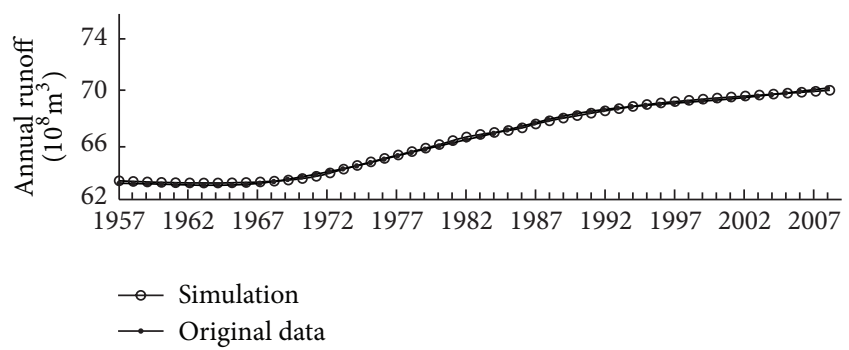

(e) S5 (the time scale of 32-year)

FIgURE 3: The simulated value for $\mathrm{AR}$ and its original data.

higher than that at small time scale. What are the causes for this? It is difficult to thoroughly answer the question because of the nonlinear complicated climatic-hydrological process, which is essentially difficult to precisely predict [15].

Our study revealed that the climatic-hydrological process at larger time scale (e.g., 16-year or 32-year scales) basically presented a linear process, but that at smaller time scale (e.g., 2-year or 4-year scales) is essentially nonlinear process with complicated causations. Because the time series of runoff are essentially monotonic trends related to long-term climatic changes at large time scale (e.g., 16-year and 32-year scales), the estimated precision is much higher. Otherwise, 
TABLE 2: MLREs for climatic-hydrological process at different time scales.

\begin{tabular}{lcccccc}
\hline Time scale & Regression equation & $R^{2}$ & $F$ & Significance level $\alpha$ & Average absolute error & Average relative error \\
\hline S1 & $\mathrm{AR}=3.243 \mathrm{AAT}+54.89$ & 0.361 & 4.763 & 0.01 & 6.266 & $9.665 \%$ \\
$\mathrm{~S} 2$ & $\mathrm{AR}=2.883 \mathrm{AAT}+0.173 \mathrm{AP}+43.62$ & 0.4157 & 15.6492 & 0.001 & 3.250 & $4.959 \%$ \\
$\mathrm{~S} 3$ & $\mathrm{AR}=5.792 \mathrm{AAT}+0.116 \mathrm{AP}+37.276$ & 0.894 & 205.729 & 0.001 & 0.880 & $1.354 \%$ \\
$\mathrm{~S} 4$ & $\mathrm{AR}=3.332 \mathrm{AAT}+0.189 \mathrm{AP}+40.618$ & 0.975 & 943.228 & 0.001 & 0.329 & $0.502 \%$ \\
S5 & $\mathrm{AR}=2.555 \mathrm{AAT}+0.206 \mathrm{AP}+42.353$ & 0.996 & 6701.914 & 0.001 & 0.109 & $0.165 \%$ \\
\hline
\end{tabular}

Notes. AR: annual runoff, AAT: annual average temperature, and AP: annual precipitation.

TABLE 3: $R^{2}$ and AIC for MLREs at different time scales.

\begin{tabular}{lcc}
\hline Time scale & $R^{2}$ & AIC \\
\hline S1 & 0.361 & 209.924 \\
S2 & 0.416 & 143.263 \\
S3 & 0.894 & 12.960 \\
S4 & 0.975 & -96.714 \\
S5 & 0.996 & -209.172 \\
\hline
\end{tabular}

due to the difficulty to accurately predict nonlinear climatichydrological process at small time scales (e.g., 2-year or 4year scale), the estimated precision and simulated effect are not satisfactory.

Nevertheless, the comprehensive method conducted by this paper provides a method to understand the climatichydrological process in the Yarkand River from the perspective of multiscale, which may be used to explore the climatichydrological process in other inland rivers of northwest China.

The main conclusions of this work can be summarized as follows.

(1) The hydrologic and climatic variables, that is, annual runoff (AR), annual average temperature (AAT), and annual precipitation (AP) are stochastic and show no significant autocorrelation.

(2) The variation pattern of runoff, temperature, and precipitation was scale dependent with time. The annual runoff (AR), annual average temperature (AAT), and annual precipitation (AP) basically present linear trends at 16-year and 32-year scales, but they show nonlinear fluctuations at 2-year, 4-year, and 8-year scales.

(3) The relationship between AR with AAT and AP was simulated by the multiple linear regression equation (MLRE) based on wavelet analysis at each time scale. The results showed that the AR is basically monotonic trend related to long-term climatic changes at a larger time scale (e.g., 16-year or 32-year scales), and the estimated precision is much higher. But due to an essentially nonlinear climatic-hydrological process at a smaller time scale (e.g., 2-year or 4-year scales), the estimated precision is lower than that at a larger time scale.

\section{Acknowledgments}

This work was supported by the Director Fund of the Key Lab of GIScience of the Education Ministry PRC. The authors are grateful to the editor and referees whose comments helped us in improving the article's quality.

\section{References}

[1] A. J. Cannon and I. G. McKendry, "A graphical sensitivity analysis for statistical climate models: application to Indian monsoon rainfall prediction by artificial neural networks and multiple linear regression models," International Journal of Climatology, vol. 22, no. 13, pp. 1687-1708, 2002.

[2] J. H. Xu, Y. N. Chen, W. H. Li, Q. Nie, Y. L. Hong, and Y. Yang, "The nonlinear hydro-climatic process in the Yarkand River, northwestern China," Stochastic Environmental Research and Risk Assessment, vol. 27, no. 2, pp. 389-399, 2013.

[3] R. Ibbitt and R. Woods, "Re-scaling the topographic index to improve the representation of physical processes in catchment models," Journal of Hydrology, vol. 293, no. 1-4, pp. 205-218, 2004.

[4] W. G. Strupczewski, V. P. Singh, S. Weglarczyk, K. Kochanek, and H. T. Mitosek, "Complementary aspects of linear flood routing modelling and flood frequency analysis," Hydrological Processes, vol. 20, no. 16, pp. 3535-3554, 2006.

[5] B. Sivakumar, "Nonlinear determinism in river flow: prediction as a possible indicator," Earth Surface Processes and Landforms, vol. 32, no. 7, pp. 969-979, 2007.

[6] J. H. Xu, Y. N. Chen, W. H. Li, and S. Dong, "Long-term trend and fractal of annual runoff process in mainstream of Tarim River," Chinese Geographical Science, vol. 18, no. 1, pp. 77-84, 2008.

[7] B. P. Wilcox, M. S. Seyfried, and T. H. Matison, "Searching for chaotic dynamics in snowmelt runoff," Water Resources Research, vol. 27, no. 6, pp. 1005-1010, 1991.

[8] J. W. Kantelhardt, D. Rybski, S. A. Zschiegner et al., "Multifractality of river runoff and precipitation: comparison of fluctuation analysis and wavelet methods," Physica A, vol. 330, no. 1-2, pp. 240-245, 2003.

[9] J. H. Xu, Y. N. Chen, W. H. Li, M. H. Ji, and S. Dong, "The complex nonlinear systems with fractal as well as chaotic dynamics of annual runoff processes in the three headwaters of the Tarim River," Journal of Geographical Sciences, vol. 19, no. 1, pp. 25-35, 2009.

[10] Z. L. Wang and C. Y. Huang, "Self-organized criticality of rainfall in central China," Advances in Meteorology, vol. 2012, Article ID 203682, 8 pages, 2012.

[11] L. C. Smith, D. L. Turcotte, and B. L. Isacks, "Streamflow characterization and feature detection using a discrete wavelet 
transform," Hydrological Processes, vol. 12, no. 2, pp. 233-249, 1998.

[12] C. M. Chou, "Efficient nonlinear modeling of rainfall-runoff process using wavelet compression," Journal of Hydrology, vol. 332, no. 3-4, pp. 442-455, 2007.

[13] J. H. Xu, Y. N. Chen, M. H. Ji, and F. Lu, "Climate change and its effects on runoff of Kaidu River, Xinjiang, China: a multiple time-scale analysis," Chinese Geographical Science, vol. 18, no. 4, pp. 331-339, 2008.

[14] C. H. Hu, Y. H. Hao, T. C. J. Yeh, B. Pang, and Z. N. Wu, "Simulation of spring flows from a karst aquifer with an artificial neural network," Hydrological Processes, vol. 22, no. 5, pp. 596604, 2008.

[15] J. H. Xu, Y. N. Chen, W. H. Li et al., "Combining BPANN and wavelet analysis to simulate hydro-climatic process-a case study of the Kaidu River, NW China," Frontiers of Earth Science, 2013.

[16] J. H. Xu, Y. N. Chen, W. H. Li, M. H. Ji, S. Dong, and Y. L. Hong, "Wavelet analysis and nonparametric test for climate change in Tarim River Basin of Xinjiang during 1959-2006," Chinese Geographical Science, vol. 19, no. 4, pp. 306-313, 2009.

[17] J. H. Xu, W. H. Li, M. H. Ji, F. Lu, and S. Dong, "A comprehensive approach to characterization of the nonlinearity of runoff in the headwaters of the Tarim River, western China," Hydrological Processes, vol. 24, no. 2, pp. 136-146, 2010.

[18] J. H. Xu, Y. N. Chen, F. Lu, W. H. Li, L. J. Zhang, and Y. L. Hong, "The nonlinear trend of runoff and its response to climate change in the Aksu River, western China," International Journal of Climatology, vol. 31, no. 5, pp. 687-695, 2011.

[19] J. H. Xu, Y. N. Chen, W. H. Li, Y. Yang, and Y. L. Hong, "An integrated statistical approach to identify the nonlinear trend of runoff in the Hotan River and its relation with climatic factors," Stochastic Environmental Research and Risk Assessment, vol. 25, no. 2, pp. 223-233, 2011.

[20] X. M. Hao, Y. N. Chen, C. C. Xu, and W. H. Li, "Impacts of climate change and human activities on the surface runoff in the Tarim River Basin over the last fifty years," Water Resources Management, vol. 22, no. 9, pp. 1159-1171, 2008.

[21] Y. N. Chen and Z. X. Xu, "Plausible impact of global climate change on water resources in the Tarim River Basin," Science in China D, vol. 48, no. 1, pp. 65-73, 2005.

[22] Y. N. Chen, K. Takeuchi, C. C. Xu, Y. P. Chen, and Z. X. Xu, "Regional climate change and its effects on river runoff in the Tarim Basin, China," Hydrological Processes, vol. 20, no. 10, pp. 2207-2216, 2006.

[23] Y. N. Chen, C. C. Xu, X. M. Hao et al., "Fifty-year climate change and its effect on annual runoff in the Tarim River Basin, China," Quaternary International, vol. 208, no. 1-2, pp. 53-61, 2009.

[24] J. Wang, H. Li, and X. Hao, "Responses of snowmelt runoff to climatic change in an inland river basin, Northwestern China, over the past 50 years," Hydrology and Earth System Sciences, vol. 14, no. 10, pp. 1979-1987, 2010.

[25] Q. Zhang, C. Y. Xu, H. Tao, T. Jiang, and Y. D. Chen, "Climate changes and their impacts on water resources in the arid regions: a case study of the Tarim River basin, China," Stochastic Environmental Research and Risk Assessment, vol. 24, no. 3, pp. 349-358, 2010.

[26] Y. F. Shi, Y. P. Shen, E. S. Kang et al., "Recent and future climate change in northwest china," Climatic Change, vol. 80, no. 3-4, pp. 379-393, 2007.
[27] B. F. Li, Y. N. Chen, Z. S. Chen, and W. H. Li, “Trends in runoff versus climate change in typical rivers in the arid region of northwest China," Quaternary International, vol. 282, pp. 87-95, 2012.

[28] B. F. Li, Y. N. Chen, and X. Shi, "Why does the temperature rise faster in the arid region of northwest China?" Journal of Geophysical Research, vol. 117, no. 16, Article ID 16115, 2012.

[29] Y. Yang, J. H. Xu, Y. L. Hong, and G. H. Lv, “The dynamic of vegetation coverage and its response to climate factors in Inner Mongolia, China," Stochastic Environmental Research and Risk Assessment, vol. 26, no. 3, pp. 357-373, 2012.

[30] Y. N. Chen, K. Takeuchi, C. C. Xu, Y. P. Chen, and Z. X. Xu, "Regional climate change and its effects on river runoff in the Tarim Basin, China," Hydrological Processes, vol. 20, no. 10, pp. 2207-2216, 2006.

[31] B. G. Sun, W. Y. Mao, Y. R. Feng et al., "study on the change of air temperature, precipitation and runoff volume in the Yarkant River basin," Arid Zone Research, vol. 23, no. 2, pp. 203-209, 2006 (Chinese).

[32] M. Sabit and A. Tohti, "An analysis of water resources and it's hydrological characteristic of Yarkend River Valley," Journal of Xinjiang Normal University, vol. 24, no. 1, pp. 74-78, 2005 (Chinese).

[33] T. L. Liu, Q. Yang, R. Qin, Y. P. He, and R. Liu, "Climate change towards warming-wetting trend and its effects on runoff at the headwater region of the Yarkand River in Xinjiang," Journal of Arid Land Resources and Environment, vol. 22, no. 9, pp. 49-53, 2008 (Chinese).

[34] J. Durbin and G. S. Watson, "Testing for serial correlation in least squares regression. I," Biometrika, vol. 37, no. 3-4, pp. 409428, 1950.

[35] J. Durbin and G. S. Watson, "Testing for serial correlation in least squares regression. II," Biometrika, vol. 38, no. 1-2, pp. 159178, 1951.

[36] D. Labat, "Recent advances in wavelet analyses: part 1. A review of concepts," Journal of Hydrology, vol. 314, no. 1-4, pp. 275-288, 2005.

[37] C. Torrence and G. P. Compo, "A practical guide to wavelet analysis," Bulletin of the American Meteorological Society, vol. 79, no. 1, pp. 61-78, 1998.

[38] M. Farge, "Wavelet transforms and their applications to turbulence," Annual Review of Fluid Mechanics, vol. 24, no. 1, pp. 395457, 1992.

[39] J. B. Ramsey, "Regression over timescale decompositions: a sampling analysis of distributional properties," Economic Systems Research, vol. 11, no. 2, pp. 163-183, 1999.

[40] J. H. Xu, Y. Lu, F. L. Su, and N. S. Ai, "R/S and wavelet analysis on the evolutionary process of regional economic disparity in China during the past 50 years," Chinese Geographical Science, vol. 14, no. 3, pp. 193-201, 2004.

[41] I. Daubechies, "Orthonormal bases of compactly supported wavelets," Communications on Pure and Applied Mathematics, vol. 41, pp. 909-996, 1988.

[42] S. G. Mallat, "Theory for multiresolution signal decomposition: the wavelet representation," IEEE Transactions on Pattern Analysis and Machine Intelligence, vol. 11, no. 7, pp. 674-693, 1989.

[43] L. M. Bruce, C. H. Koger, and J. Li, "Dimensionality reduction of hyperspectral data using discrete wavelet transform feature extraction," IEEE Transactions on Geoscience and Remote Sensing, vol. 40, no. 10, pp. 2331-2338, 2002. 
[44] J. H. Xu, Y. N. Chen, M. H. Ji, and F. Lu, "Climate change and its effects on runoff of Kaidu River, Xinjiang, China: a multiple time-scale analysis," Chinese Geographical Science, vol. 18, no. 4, pp. 331-339, 2008.

[45] J. H. Xu, Mathematical Methods in Contemporary Geography, Higher Education Press, Beijing, China, 2002, (in Chinese).

[46] D. R. Anderson, K. P. Burnham, and W. L. Thompson, "Null hypothesis testing: problems, prevalence, and an alternative," Journal of Wildlife Management, vol. 64, no. 4, pp. 912-923, 2000.

[47] K. P. Burnham and D. R. Anderson, Model Selection and Multimodel Inference: A Practical Information-Theoretic Method, Springer, New York, NY, USA, 2nd edition, 2002.

[48] X. Wang, Z. C. Xie, S. Y. Liu, D. H. Shangguan, J. J. Tao, and Y. L. Yang, "Prediction on the variation trend of glacier system in the source region of Tarim River responding to climate change," Journal of Mountain Research, vol. 24, no. 6, pp. 641-646, 2006 (Chinese). 

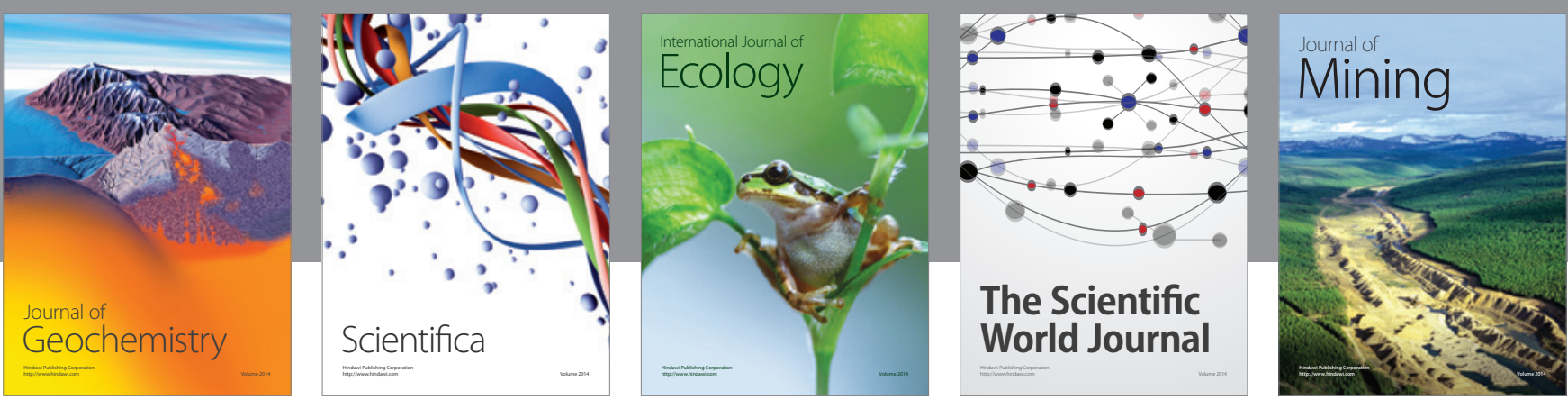

The Scientific World Journal
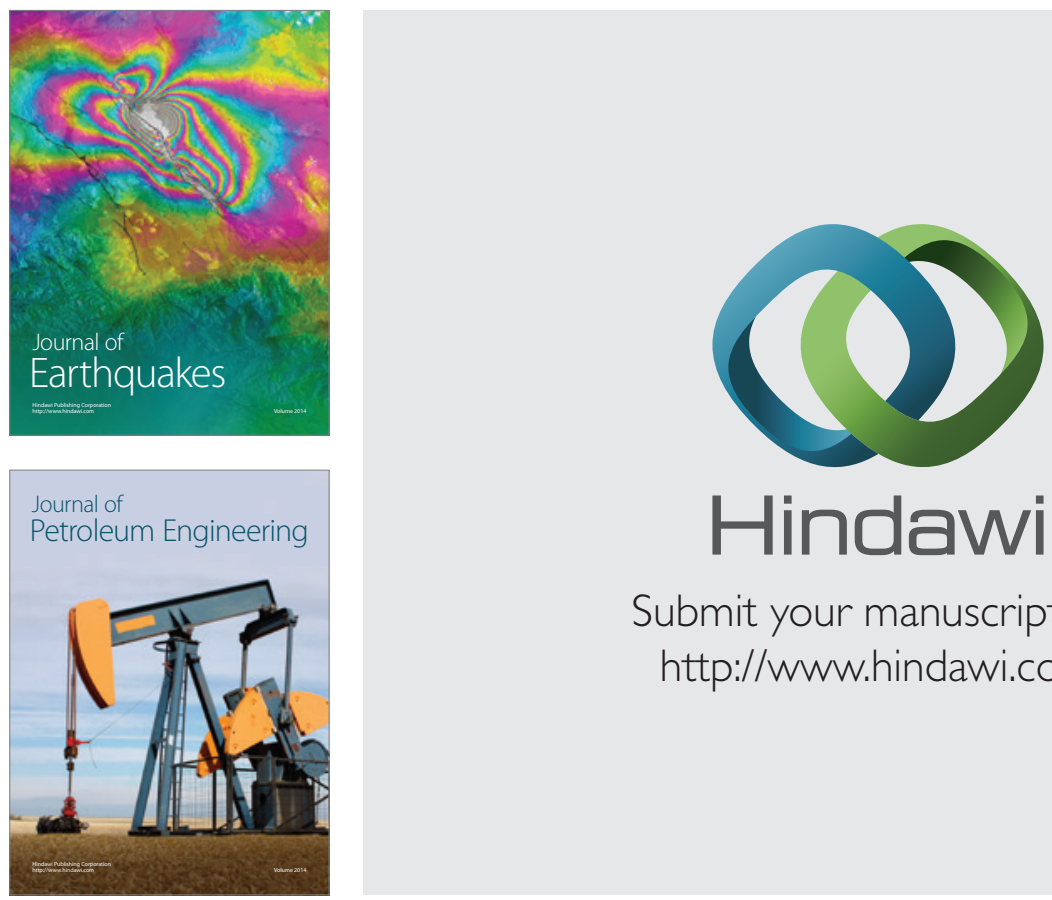

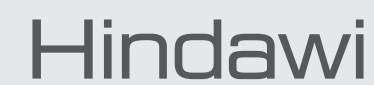

Submit your manuscripts at

http://www.hindawi.com
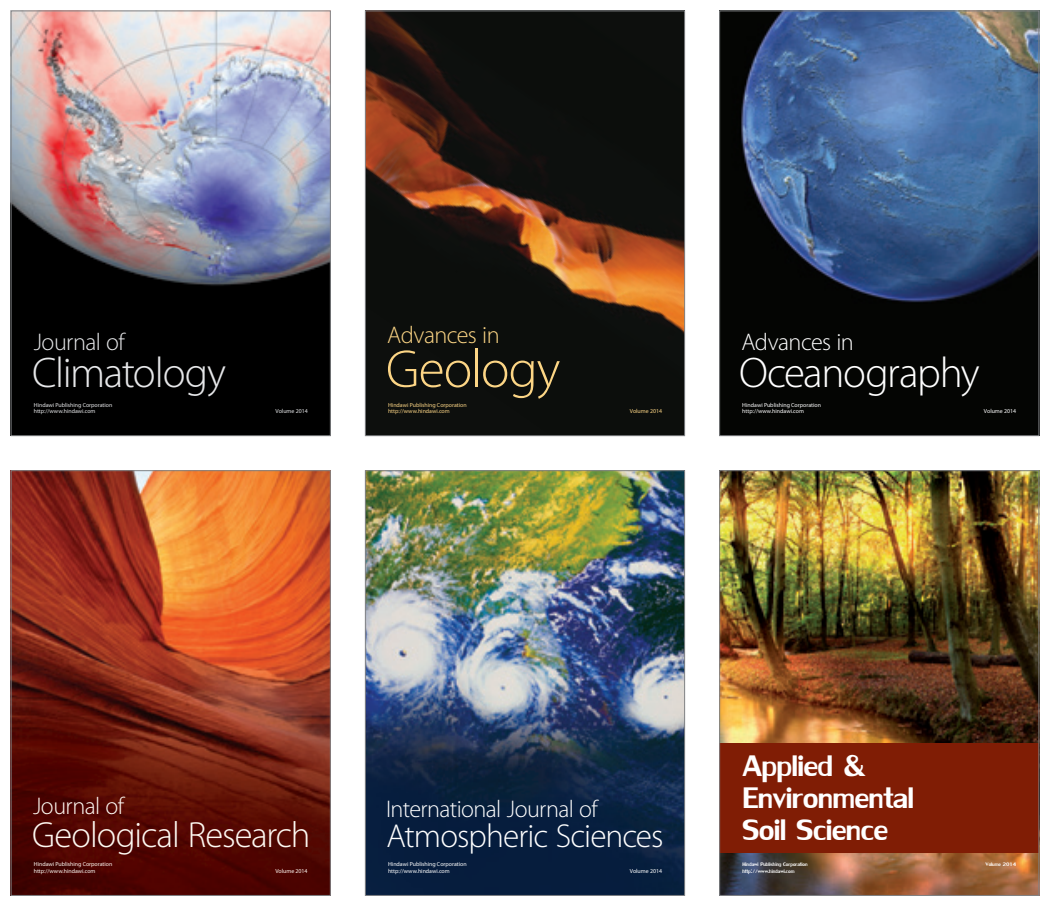
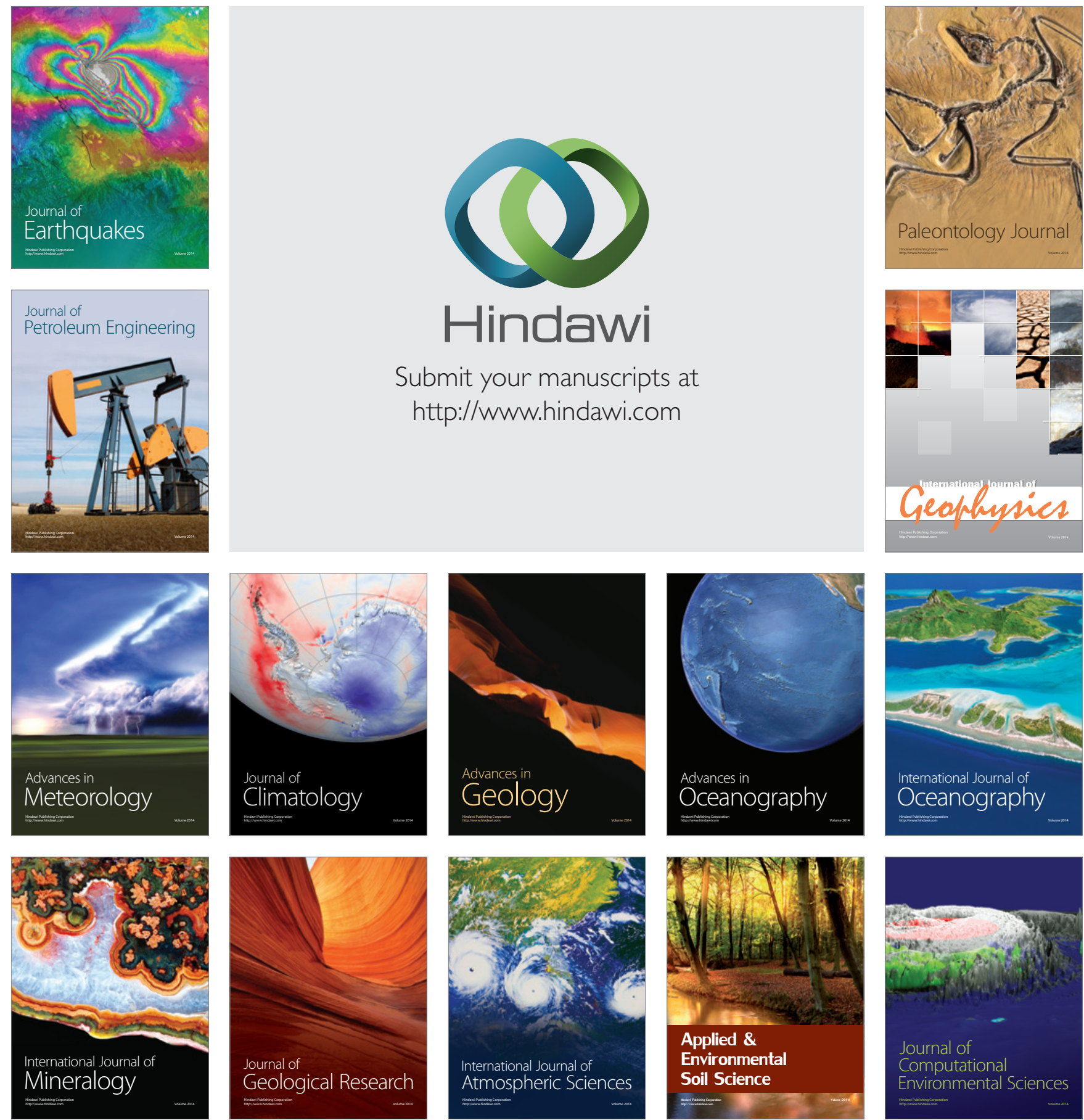